\title{
ROSTER OF TECHNICAL PERSONNEL
}

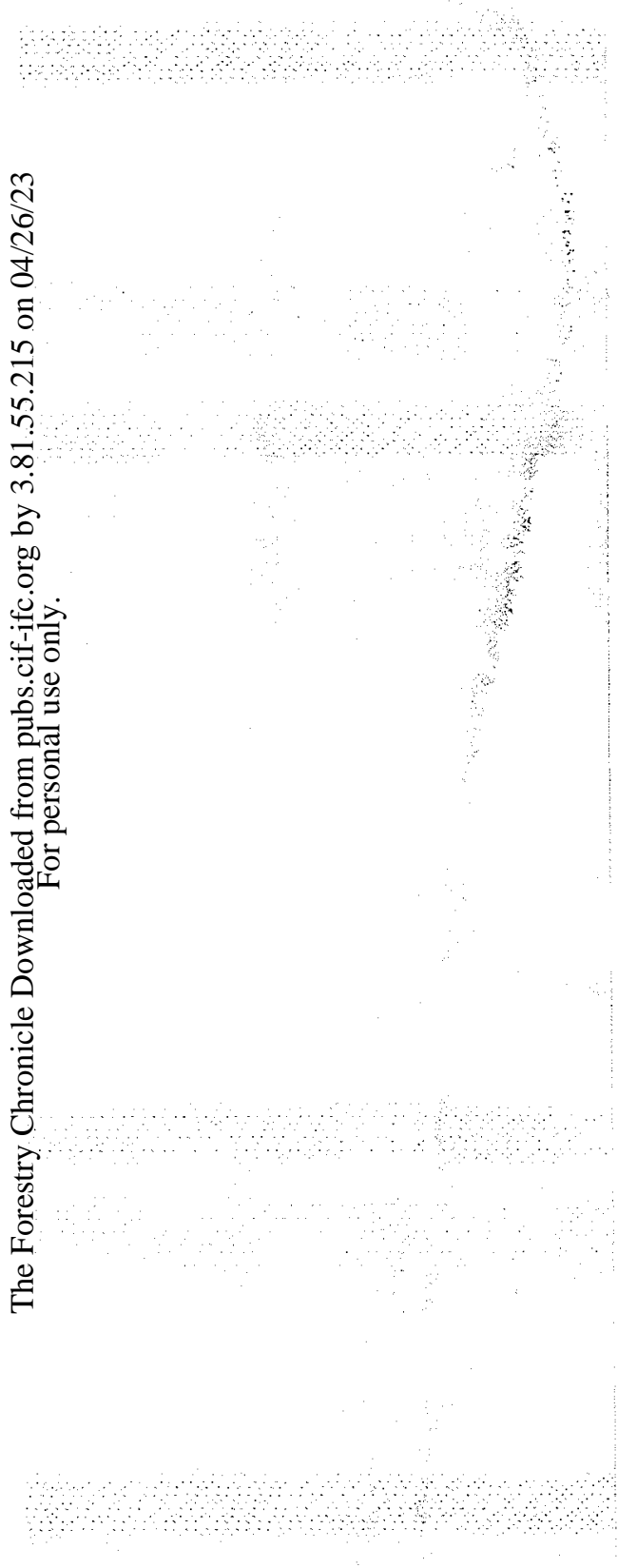

Dr. R. E. Balch, President,

Ottawa,

and Members of the Board of Directors,

April 6, 1951

The Canadian Institute of Forestry,

10 Manor Road West,

TORONTO, Ontario.

Gentlemen:

As you will no doubt have learned from recent public announcements, the Department of Labour is embarking on a project to review the records of technical and scientific personnel in Canada with the object of bringing them up to date. Each such person will shortly be given the opportunity to co-operate in this task by listing his particulars as of 1951 on an appropriate questionnaire form.

In view of the whole-hearted co-operation received from your Institute and its members when the roster of technical personnel was first built up during World War II, I do not hesitate to request your assistance in this 1951 programme. Speaking for both my Department and for the Government, I can assure you it is realized that the sympathetic support of all professional societies involved is of the greatest importance to the effectiveness of this plan. With this in mind, it would be appreciated if you could find occasion to refer to the matter in an early issue of your official publication requesting each member to do his part by completing and returning the questionnaire when it is received.

As the new records are compiled, we shall be in a position to arrive at an up-to-date assessment of existing resources of skill as possessed by this important segment of Canadian manpower.

Yours very truly,

Signed-Milton F. Gregg

Minister of Labour,

Ottawa.

BOOK REVIEWS

Forest Mensuration by Donald Bruce and Francis X. Schumacher (McGraw-Hill Book Company, Inc., Toronto, 1950. 483 pp.)

In this new third edition the authors again place particular emphasis on the tools used in the science of forest mensuration. By departing from the conventional economic approach the presentation gains in simplicity and clarity. However there is a loss in detail and in emphasis of the correlations between mensuration, silviculture and management.

Careful treatment is given to the use of the standard tools of forest mensuration, cross-section paper, simple and harmonized curves, sample plots and strip surveys, and the actual physical instruments such as caliper, tape, scale stick and hypsometer. Graphic solutions which require alinement charts and anamorphosis are given complete and detailed study.

Although the approach to elementary statistics is graphical and does not lead readily into advanced study, the treatment is concise and easily understood. 